\title{
Genetics of Dentofacial and Orthodontic Abnormalities
}

\author{
Praveen Kumar Neela ${ }^{1}$ Anjana Atteeri ${ }^{1}$ Pavan Kumar Mamillapalli ${ }^{1}$ Vasu Murthy Sesham ${ }^{1}$ \\ Sreekanth Keesara ${ }^{1}$ Jaya Chandra ${ }^{1}$ Udayini Monica ${ }^{1}$ Vasavi Mohan ${ }^{2}$ \\ ${ }^{1}$ Department of Orthodontics, Kamineni Institute of Dental Sciences, \\ Narketpally, India \\ 2 Department of Genetics and Molecular Medicine, Vasavi Medical and \\ Address for correspondence Praveen Kumar Neela, BDS, MDS, DIBO, \\ M(Orth) RCPS (Glasg), Department of Orthodontics, Kamineni \\ Research Centre, Hyderabad, Telangana, India \\ Institute of Dental Sciences, Narketpally 508254, Telengana, India \\ (e-mail: praveenneela@yahoo.com).
}

Global Med Genet 2020;7:95-100.

\begin{abstract}
Keywords

- genetics

- genes

- polymorphism

- dentofacial variations

- malocclusion

The development of craniofacial complex and dental structures is a complex and delicate process guided by specific genetic mechanisms. Genetic and environmental factors can influence the execution of these mechanisms and result in abnormalities. An insight into the mechanisms and genes involved in the development of orofacial and dental structures has gradually gained by pedigree analysis of families and twin studies as well as experimental studies on vertebrate models. The development of novel treatment techniques depends on in-depth knowledge of the various molecular or cellular processes and genes involved in the development of the orofacial complex. This review article focuses on the role of genes in the development of nonsyndromic orofacial, dentofacial variations, malocclusions, excluding cleft lip palate, and the advancements in the field of molecular genetics and its application to obtain better treatment outcomes.
\end{abstract}

\section{Introduction}

Genetics as an etiological factor plays a crucial role in the development of jaws, both maxilla, and mandible, dentition, and occlusion. In 1836, Frederick Kussel reported that malocclusion, both skeletal and dental, could be transmitted from one generation to another and also stated that chromosomal defects account for approximately $10 \%$ of all malocclusions. ${ }^{1}$ The pioneering work of Gregor Johann Mendel initiated an interest in the field of genetics in the 19th century, and since then, genetics has been an essential part of the studies performed in various fields of biological and medical sciences. Since the 20th century, this branch of science has evolved through a series of era-based conceptual breakthroughs. Lack of sufficient understanding of principles of inheritance in the past led to a view regarding genetics and malocclusion remaining unclear. ${ }^{2}$

published online

February 1, 2021
DOI https://doi.org/

10.1055/s-0040-1722303.

ISSN 2699-9404.
Understanding the genetic factors contributing to the variation in dentofacial morphology associated with malocclusions is the key for proper diagnosis which, in turn, helps to develop novel treatment techniques. Advances in dentofacial phenotyping, which is the comprehensive characterization of hard- and soft-tissue variation in the craniofacial complex, together with the acquisition of largescale genomic data have started to unravel genetic mechanisms underlying facial variation. Knowledge of the genetics of human malocclusion is limited even though results attained thus far are encouraging, with promising opportunities for future research. ${ }^{3}$ This review article summarizes the role of genes in the development of nonsyndromic orthodontic, dentofacial variations, excluding clefts, malocclusions, and the advancements in the field of molecular genetics and its application to obtain better treatment outcomes.

\section{(c) 2021. The Author(s).}

This is an open access article published by Thieme under the terms of the Creative Commons Attribution License, permitting unrestricted use, distribution, and reproduction so long as the original work is properly cited. (https://creativecommons.org/licenses/by/4.0/)

Georg Thieme Verlag KG, Rüdigerstraße 14, 70469 Stuttgart, Germany 


\section{Genetic Influence on Skeletal Relationship of Jaws}

Mandibular prognathism is caused by a deficiency of the maxillary growth, excessive mandibular growth, or a combination of both. Familial studies of mandibular prognathism are suggestive of heredity in the etiology of this condition. Various models have been suggested, such as autosomal dominant with incomplete penetrance, simple recessive, variable both in expressivity and penetrance with differences in different racial populations. ${ }^{4}$ The familial nature of mandibular prognathism was first reported by Strohmayer as noted by Wolff et al. in their analysis of the pedigree of the Habsburg family. ${ }^{5}$ The Habsburg jaw is seen in European royalty in which mandibular prognathism recurred over multiple generations. The genetic factors appear to be heterogeneous with monogenic influence (usually autosomal dominant with incomplete penetrance and variable expressivity) in some families and multifactorial (polygenic complex) influence in others. ${ }^{6}$

Although various genetic linkage analyses and genomewide association studies have identified many genes and loci associated with mandibular prognathism, the genes underlying the risk of mandibular prognathism in the general population remain ambiguous, leaving some impetus to search for new candidate genes. To date, genome-wide linkage analyses of mandibular prognathism have been performed among Japanese, Korean, Hispanic, and Chinese cohorts and several genetic loci have been reported to be associated with it, including $1 \mathrm{p} 22.1,1 \mathrm{q} 32.2,1 \mathrm{p} 36,3 \mathrm{q} 26.2$, 4p16.1, 6q25, 11q22, 12q13.13, 12q23, 14q24.3-31.2, and 19p13.2. ${ }^{7-13}$ Genome-wide linkage and association studies also found positive correlations for mandibular prognathism and genes, growth hormone receptor (GHR), ${ }^{14}$ erythrocyte membrane protein band4.1 (EPB4), ${ }^{15}$ synovial sarcoma $X$ (SSX21), myosin1 $\mathrm{H}(\mathrm{MYO} 1 \mathrm{H}),{ }^{16}$ collagen type II $\alpha 1$ (COL2A1), ${ }^{17}$ fibroblast growth factor (FGF7), ${ }^{18}$ transforming growth factor beta 3 (TGFB3), plexin A (PLXNA), latent transforming beta binding protein 2 (LTBP2), matrilin1 (MATN1), ${ }^{9}$ dual specificity phosphatase 6 (DUSP6), ${ }^{11}$ and a disintegrin and metalloproteinase with thrombospondin motifs 1 (ADAMTS1) $)^{13}$ in various populations.

\section{Vertical Skeletal Jaw Abnormalities}

Fontoura et al in their study suggested two candidate genes, PAX5, a transcription factor, and Rho GTPase activating protein 29 (ARHGAP29), which mediates the cyclical regulation of small GTP binding proteins such as RhoA, are associated with the vertical discrepancies, ranging from skeletal deep bite to open bite. ${ }^{19}$ Manfredi et al in a more recent study on monozygotic twins, dizygotic twins, and same-sex siblings, assessed the inheritance traits of the orthodontic cephalometric parameters. They also suggested that the vertical parameters were more genetically controlled than the anteroposterior ones; heritability seemed to be expressed more anteriorly than posteriorly. The mandibular shape seemed to be determined more genetically than the mandibular size. ${ }^{20}$ Savoye et al also reported similar findings and stated that the vertical proportions are highly under genetic control. ${ }^{21}$

\section{Genetic Effects on Individual Tooth Variations}

Genetic factors control the tooth size, morphology, number, position, and its inheritance, as stated in various twin studies. ${ }^{22-24}$ HOX genes, which play a fundamental role in the oral and dental development, are known to show sitespecific anteroposterior expression patterns. Molecular genetics of tooth morphogenesis, with the homeostatic Hox 7 and Hox 8 (presently MSX1 and MSX2) genes being responsible for stability in dental patterning, is confirmation of Butler's field theory. ${ }^{25}$

A supernumerary tooth, which is most frequently seen in the premaxillary region with a greater prevalence for males, also appears to be genetically determined. Niswander and Sujaku ${ }^{26}$ in 1963 analyzed data from family studies, and they suggested that, like hypodontia, the genetics of less prevalent condition of supernumerary teeth is under control of several genes in different loci and may be associated with an autosomal recessive gene with lesser penetrance in females. This was later supported by Galas and Garcia in 1999. ${ }^{27}$ While an autosomal dominant inheritance with incomplete penetrance has been suggested, the increased incidence in males suggests the possibility of sex-linked heredity, as stated by Bruning et al. Although this inheritance does not follow a simple Mendelian pattern, these are more commonly present in parents and siblings of patients who present with this condition. Evidence from twins with supernumerary teeth also supports this theory. ${ }^{28}$

Dental agenesis, which is the most common developmental anomaly seen in humans, is genetically and phenotypically a heterogeneous condition. Based on the current knowledge of genes and the factors involved in the tooth development and morphogenesis, it is assumed that different phenotypic forms are caused by different genes involving different interacting molecular pathways, providing an explanation not only for the wide variety in agenesis patterns but also for associations of dental agenesis with other oral anomalies. More than 200 genes have so far been identified, which are expressed during tooth development, and mutations in several of these genes are known to cause arrested tooth development in mice. ${ }^{29}$

Population studies have shown that tooth agenesis can be manifested as an isolated trait or part of a syndrome. Isolated forms may be either sporadic or familial. Familial tooth agenesis can be the result of a single dominant gene defect or recessive or X-linked. Third molar agenesis cannot be explained in most of the cases with a simple model of autosomal dominant transmission. Besides, a polygenic mode of inheritance has also been reported in the literature. Grahnen ${ }^{30}$ stated that tooth agenesis is typically transmitted as an autosomal dominant trait with incomplete penetrance and variable expressivity. Twin studies have been widely used to show the importance of the genetic component involved 
during tooth development to control both tooth size and form. There are numerous case reports, suggesting concordance for tooth agenesis in monozygotic twins, and case reports where variation in the expressivity is observed. ${ }^{31}$

Numerous mutations in transcription factor and growth factor-related genes involved in dental development have been shown to play a role in human dental agenesis, including paired box 9 (PAX9), a transcription factor, and muscle segment homeobox 1 (MSX1). MSX1 gene mutations can lead to hypodontia or oligodontia as well as variations in the downstream signaling gene bone morphogenetic protein 4 (BMP4). In humans, a point mutation in MSX1 homeobox results in agenesis of second premolars and third molars in affected individuals. $^{25}$

Mutations in PAX9 typically show a nonsyndromic autosomal dominant mode of inheritance for oligodontia, with variable expressivity within families. The characteristic pattern of dental agenesis caused by PAX9 mutations primarily affects molars in both dental arches and second premolars most often in the maxillary arch than the mandibular arch, occasionally presenting with missing or pegshaped mandibular central incisors and maxillary lateral incisors. Agenesis of maxillary first premolars or canines can occur with a low frequency among PAX9 mutations. In contrast, the PAX9 Ala240Pro mutation may be unique, in that it leads uniquely to third molar agenesis with or without affected incisors. Mutations in the axis inhibitor 2 gene (AXIN2) have also been linked to oligodontia, often exhibiting a similar pattern of affected teeth as PAX9 mutations. $^{32}$ From this, it is clear that the functions of PAX9 and MSX1 are essential for the establishment of the odontogenic potential of the mesenchyme through the maintenance of mesenchymal Bmp4 expression. However, the relationship between these three genes on the molecular level remains unknown.

Primary failure of eruption (PFE), which was described initially by Profitt and Vig, ${ }^{33}$ is characterized by nonsyndromic eruption failure of permanent teeth in the absence of mechanical obstruction. Many studies have stated the heritable basis of this dental phenotype, and recently, mutations in parathyroid hormone receptor 1 (PTH1R) have been identified. It functions in signaling in mesenchymal progenitors, alveolar bone formation, and periodontal ligament development during eruption physiology. The recent report of PTH1R mutations associated with primary failure of eruption makes this a high-priority candidate gene for confirming the diagnosis of a nonsyndromic PFE phenotype. ${ }^{34}$

Crowding of teeth is a complex dental anomaly that affects esthetics and quality of life. Crowding is usually caused by insufficient arch space that cannot accommodate all erupting permanent teeth. Genetics is suggested to contribute to the etiology of crowding. A study conducted by Ting et al suggested a significant association for the genes ectodysplasin A (EDA) and X-linked ectodermal dysplasia receptor (XEDAR), which are important in the signaling pathway that plays a role in the development of dental crowding among the Hong Kong Chinese population. Since this association study was done in the Hong Kong Chinese population, the results might not apply to other ethnic groups. Further replication studies in other ethnic groups with a larger sample size are vital for confirmation of these findings. $^{35}$

A genetic tendency for ectopic maxillary canines has also been reported in various association studies. ${ }^{36}$ Peck et al concluded that palatally ectopic canines, as an inherited trait, is one of the anomalies in a complex of genetically related dental disturbances, often occurring in combination with missing teeth, tooth size reduction, supernumerary teeth, and other ectopically positioned teeth. ${ }^{37}$ Previous studies have also shown an association between ectopic maxillary canines and class II division 2 malocclusion, a genetically inherited trait. ${ }^{38}$

Genetic variation showing a significant effect on arch width and length was confirmed in various studies on monozygotic and dizygotic twins. A genetic contribution to arch shape was found by Richards et al after comparing the intraclass correlations between monozygotic and dizygotic South Australian twins. ${ }^{39}$

A study was conducted by Corruccini et al on the occlusal characteristics in 32 pairs of monozygotic twins and 28 pairs of dizygotic twins using dental stone casts. They studied arch shape, size, and symmetry, overjet, overbite, posterior crossbite, buccal segment relation, rotation, and displacements. They concluded that arch size variation, tooth displacement, and crossbite showed significant genetic variance and also found an increased environmental component of variance in occlusion. ${ }^{40}$ A study on north-west Indian twins revealed significant genetic variance for dental arch and palate dimensions, but environmental influences seemed important for occlusal traits. ${ }^{41}$

\section{Effects of Genetics on Inheritance of Malocclusion}

Malocclusion is a significant deviation from an ideal or normal occlusion. ${ }^{38}$ Malocclusion can either be skeletal or dental, involving discrepancies in the jaw size, tooth size, and shape, crowding, or spacing. It is a manifestation of both genetic factors and environmental influences during the development of the craniofacial complex. However, it might be difficult to differentiate whether the malocclusions are determined by the genetic code or environmental factors, or a combination of both. ${ }^{42}$ The concepts and principles of molecular genetics have become significant components in the understanding of the genesis of variations in the growth, development, and form of the entire craniofacial complex.

Genetic factors playing a predominant role in the etiology of malocclusion is backed by population studies, especially family and twin studies. ${ }^{43}$ Familial aggregation studies suggested that an autosomal dominant model with incomplete penetrance has the most significant validity for Class III pedigrees, including the royal Habsburg family ${ }^{5}$ and others from middle Eastern, ${ }^{44}$ South American, ${ }^{16,45}$ and Eastern European descent. In contrast, polygenic inheritance and 
autosomal dominance models, with incomplete penetrance and variable expressivity, have been suggested for Class II division 1 and 2, respectively. ${ }^{46}$ Lauweryns in 1993 reported that $40 \%$ of the dental and skeletal variations that lead to malocclusion could be attributed to genetic factors. ${ }^{47}$

Extensive cephalometric studies by Harris suggested the concept of polygenic inheritance for Class II division 1 malocclusion, showing that the craniofacial skeletal patterns of children with class II malocclusions are heritable and that there is a high resemblance to the skeletal patterns in their siblings with normal occlusion. ${ }^{48}$

Familial occurrence of Class II division 2 has been documented in several published reports including twin and triplet studies (Kloeppel; Markovic) and family pedigrees from Korkhaus, Rubbrecht, Trauner, ${ }^{49}$ and Peck et al. ${ }^{50}$ Twin studies showed that the identical twins demonstrated 100\% concordance for Class II division 2 malocclusion, indicating a strong genetic influence in the development of Class II division 2 deep bite malocclusions. ${ }^{51}$ Markovic's clinical and cephalometric study of intra- and interpair comparisons of 114 Class II division 2 malocclusions, 48 twin pairs, and six sets of triplets showed complete penetrance and variable expressivity of autosomal dominant genetic impression. ${ }^{52}$ The controversy regarding the etiology of the Class II Division 2 malocclusion arises from a failure to appreciate the synergistic effects of genetics and the environment on facial morphology. Ballard, Houston, Mills, ${ }^{53}$ and others considered that a high lip line and a particular lip morphology and behavior were the main etiological factors. Graber, Hotz, Meskov and Markovic ${ }^{54}$ stressed the predominant role of genetic factors in the etiology of Class II division 2 malocclusions.

Nakashima et al. ${ }^{55}$ conducted a study to assess the role of heredity in the development of Angle's Class II and Class Ill malocclusions, and their results showed that: 1 ) The parents of Class II patients had a convex profile with a distocclusion type of denture pattern, while the parents of Class III patients had a concave profile with a mesiocclusion type of denture pattern, suggesting both Class II and Class III malocclusions have a genetic basis. These correlations between parent and offspring were stronger for the skeletal measurements in both classes. 2) The correlation coefficients in the parentoffspring data were in good agreement with the expected level under the polygenic model of inheritance. 3) Significant differences between Class II and III patients for four variables (upper incisor to NA angle, gonial angle, Ar-Go, and upper incisor to nasal floor angle) were considered to be related to environmental factors. ${ }^{55}$

\section{Genetic Effects on External Apical Root Resorption}

Evidence from previous studies suggest that genetic factors play a significant role in the development of root resorption. ${ }^{56}$ Al-Qawasmi and colleagues in 2003 performed a family study to assess the potential effect of single nucleotide polymorphisms (SNPs) in two closely-located proinflammatory candidate genes (IL-1A and IL-B) on root resorption and found that patients who were homozygous for IL-1B allele 1 have a 5.6 fold (95\% CI 1.9-21.2) increased risk of apical root resorption (ARR) compared with those who were not homozygous for the IL-1B allele. ${ }^{57}$ Another candidate locus identified to be associated with the development of ARR is located on chromosome 18 and showed evidence for linkage between a microsatellite marker D18S64, which lies close to the candidate gene TNF receptor superfamily member 11a (TNFRSF11A) and root resorption trait. The TNFRSF11A gene encodes the receptor activator of nuclear factor-kappa B (RANK), an essential signaling molecule in osteoclast formation and activation as a potential mechanism in the pathogenesis of root resorption. ${ }^{58}$

\section{Genetic Implications on Orthodontic Tooth Movement}

Multiple molecular pathways that influence orthodontic tooth movement (OTM) are identified to date. Two of the pathways that influence both orthodontic tooth movement and external apical root resorption include the ATP/P2XR7/IL-1B inflammatory signaling pathway and the RANKL/RANK/OPG bone modelling and remodeling pathway. However, even with this knowledge of key pathways influencing OTM, few studies have focused on determining how actual variations in nonsyndromic genetic factors correlate with the actual clinical outcomes observed during OTM in humans. ${ }^{59}$ Studies have been done with genetic variation markers based on the part of the ATP/P2RX7/ IL-1B pathway, the genes for IL-1 $\beta$ and another related cytokine interleukin $1 \alpha$ IL-1 $\alpha$ (IL1B and IL1A, respectively), and the gene (IL1RN) for another molecular pathway (IL-1 receptor antagonist, IL-RA) that helps to regulate their biological activity. ${ }^{60}$ Of these two forms, interleukin $1 \beta$-IL-1 $\beta$ is the most potent for bone resorption and inhibition of bone formation. OTM requires a balance between IL-1 $\beta$ and IL-1RA synthesis for the bone modelling and remodeling processes involved. $^{61}$

\section{Conclusion}

The knowledge of the role of genetics is essential for the orthodontist which helps to understand why a patient has a particular occlusion, because malocclusion is a manifestation of genetic and environmental interaction on the development of the orofacial complex. Awareness regarding the genetic expression of the dentofacial maldevelopment is an essential aid in the correction of malocclusion, as it helps to segregate the inherited malocclusions from those due to the effect of environmental factors and thereby helps to diagnose, treat, and possibly even prevent a malocclusion from occurring in the next generation.

There has been immense progress in the field of genetically supported orthodontics to date. Although it is very challenging to reveal the genetic component of most malocclusions and dental anomalies because of its polygenic nature, data developed and provided by the human genome project have made it feasible to map inherited conditions related to the dentofacial development. 
However, further genetic studies are required to determine all the specific genes leading to a particular skeletal variability. Genome-wide association studies are necessary to evaluate further as well as provide a database for evidence-based practice.

\section{Conflict of Interest}

None declared.

\section{References}

1 Varma G, Harsha B, Palla S, Sravan S, Raju J, Rajavardhan K. Genetics in an orthodontic perspective. J Adv Clin Res Insights 2019;18(06):3

2 Carlson DS. Evolving concepts of heredity and genetics in orthodontics. Am J Orthod Dentofacial Orthop 2015;148:922-938

3 Moreno Uribe LM, Miller SF. Genetics of the dentofacial variation in human malocclusion. Orthod Craniofac Res 2015;18 (Suppl 1):91-99

4 Xue F, Wong RW, Rabie AB. Genes, genetics, and Class III malocclusion. Orthod Craniofac Res 2010;13:69-74

5 Wolff G, Wienker TF, Sander H. On the genetics of mandibular prognathism: analysis of large European noble families. J Med Genet 1993;30(02):112-116

6 Hartsfield JK Jr, Jacob GJ, Morford LA. Heredity, genetics and orthodontics: How much has this research really helped? Semin Orthod 2017;23(04):336-347

7 Yamaguchi T, Park SB, Narita A, Maki K, Inoue I. Genome-wide linkage analysis of mandibular prognathism in Korean and Japanese patients. J Dent Res 2005;84(03):255-259

8 Frazier-Bowers S, Rincon-Rodriguez R, Zhou J, Alexander K, Lange E. Evidence of linkage in a Hispanic cohort with a Class III dentofacial phenotype. J Dent Res 2009;88(01):56-60

9 Jang JY, Park EK, Ryoo HM, et al. Polymorphisms in the Matrilin-1 gene and risk of mandibular prognathism in Koreans. J Dent Res 2010;89(11):1203-1207

10 Li Q, Li X, Zhang F, Chen F. The identification of a novel locus for mandibular prognathism in the Han Chinese population. J Dent Res 2011;90(01):53-57

11 Nikopensius T, Saag M, Jagomägi T, et al. A missense mutation in DUSP6 is associated with Class III malocclusion. J Dent Res 2013; 92(10):893-898

12 Chen F, Li Q, Gu M, Li X, Yu J, Zhang Y-B. Identification of a mutation in FGF23 involved in mandibular prognathism. Sci Rep 2015;5:11250

13 Guan X, Song Y, Ott J, et al. The ADAMTS1 gene is associated with familial mandibular prognathism. J Dent Res 2015;94(09): 1196-1201

14 Bayram S, Basciftci FA, Kurar E. Relationship between P561T and C422F polymorphisms in growth hormone receptor gene and mandibular prognathism. Angle Orthod 2014;84(05):803-809

15 Xue F, Wong R, Rabie ABM. Identification of SNP markers on 1p36 and association analysis of EPB41 with mandibular prognathism in a Chinese population. Arch Oral Biol 2010;55(11):867-872

16 Cruz RM, Krieger H, Ferreira R, Mah J, Hartsfield J Jr, Oliveira S. Major gene and multifactorial inheritance of mandibular prognathism. Am J Med Genet A 2008;146A(01):71-77

17 Xue F, Rabie AB, Luo G. Analysis of the association of COL2A1 and IGF-1 with mandibular prognathism in a Chinese population. Orthod Craniofac Res 2014;17(03):144-149

18 Xiong X, Li S, Cai Y, Chen F. Targeted sequencing in FGF/FGFR genes and association analysis of variants for mandibular prognathism. Medicine (Baltimore) 2017;96(25):e7240

19 da Fontoura CSG, Miller SF, Wehby GL, Amendt BA, Holton NE, Southard TE, et al. Candidate gene analyses of skeletal variation in malocclusion. J Dent Res 2015;94(07):913-920
20 Manfredi C, Martina R, Grossi GB, Giuliani M. Heritability of 39 orthodontic cephalometric parameters on MZ, DZ twins and MNpaired singletons. Am J Orthod Dentofacial Orthop 1997;111(01): 44-51

21 Savoye I, Loos R, Carels C, Derom C, Vlietinck R. A genetic study of anteroposterior and vertical facial proportions using modelfitting. Angle Orthod 1998;68(05):467-470

22 Ludwig FJ. The mandibular second premolars: morphologic variation and inheritance. J Dent Res 1957;36:263-273

23 Osborne RH, Horowitz SL, De George FV. Genetic variation in tooth dimensions: a twin study of the permanent anterior teeth. Am J Hum Genet 1958;10:350-356

24 Lundström A. Tooth morphology as a basis for distinguishing monozygotic and dizygotic twins. Am J Hum Genet 1963; 15:34-43

25 Sharpe PT. Homeobox genes and orofacial development. Connect Tissue Res 1995;32(1-4):17-25

26 Niswander JD, Sujaku C. Congenital anomalies of teeth in Japanese children. Am J Phys Anthropol 1963;21(04):569-74. DOI: 10.1002/ajpa.1330210413

27 Gallas MM, Garcia A. Retention of permanent incisors by mesiodens: A family affair. Br Dent J 2000;188:63-64

28 Mercuri LG, O'Neill R. Multiple impacted and supernumerary teeth in sisters. Oral Surg Oral Med Oral Pathol 1980;50:293

29 De Coster PJ, Marks LA, Martens LC, Huysseune A. Dental agenesis: genetic and clinical perspectives.J Oral Pathol Med 2009;38(01):1-17

30 Grahnen H. Hypodontia in the permanent dentition: a clinical and genetical investigation. Odont Revy 1956;7:1-100

31 Vastardis H. The genetics of human tooth agenesis: new discoveries for understanding dental anomalies. Am J Orthod Dentofacial Orthop 2000;117(06):650-656

32 Vieira AR, Meira R, Modesto A, Murray JC. MSX1, PAX9, and TGFA contribute to tooth agenesis in humans. J Dent Res 2004;83(09): 723-727

33 Proffit WR, Vig KWL. Primary failure of eruption: a possible cause of posterior open-bite. Am J Orthod 1981;80:173-190

34 Decker E, Stellzig-Eisenhauer A, Fiebig BS, Rau C, Kress W, Saar K, et al. PTHR1 loss-of-function mutations in familial, nonsyndromic primary failure of tooth eruption. Am J Hum Genet 2008;83(06):781-786

35 Ting TY, Wong RWK, Rabie ABM. Analysis of genetic polymorphisms in skeletal Class I crowding. Am J Orthod Dentofacial Orthop 2011;140(01):e9-e15

36 Rutledge MS, Hartsfield JK. Genetic factors in the etiology of palatally displaced canines. Semin Orthod 2010;16(03):165-171

37 Peck S, Peck L, Kataja M. The palatally displaced canine as a dental anomaly of genetic origin. Angle Orthod 1994;64(04):249-256

38 Mossey PA. The heritability of malocclusion: part 2. The influence of genetics in malocclusion. Br J Orthod 1999;26(03):195-203

39 Eguchi S, Townsend GC, Richards LC, Hughes T, Kasai K. Genetic contribution to dental arch size variation in Australian twins. Arch Oral Biol 2004;49(12):1015-1024

40 Corruccini RS, Potter RH. Genetic analysis of occlusal variation in twins. Am J Orthod 1980;78(02):140-154

41 Corruccini RS, Sharma K, Potter RH. Comparative genetic variance and heritability of dental occlusal variables in U.S. and Northwest Indian twins. Am J Phys Anthropol 1986;70(03):293-299

42 Hartsfield JK Jr. Genetics and orthodontics. In: Graber LW, Vanarsdall RL, Vig KW, eds. Orthodontics: Current Principles and Techniques. 5th ed. St-Louis

43 Baker CR. Similarity of malocclusion in families. Int J Orthod Oral Surg Radiogr. 1924;10:459-462

44 El-Gheriani AA, Maher BS, El-Gheriani AS, Sciote JJ, Abu-shahba FA, Al-Azemi R, et al. Segregation analysis of mandibular prognathism in Libya. J Dent Res 2003;82(07):523-527

45 Otero L, Quintero L, Champsaur D, Simanca E. Inheritance of craniofacial features in Colombian families with class III malocclusion. Appl Clin Genet 2010;3:1-6 
46 Harris JE. Genetic factors in the growth of the head. Inheritance of the craniofacial complex and malocclusion. Dent Clin North Am 1975;19(01):151-160

47 Lauweryns I, Carels C, Vlietinck R. The use of twins in dentofacial genetic research. Am J Orthod Dentofacial Orthop 1993;103(01):33-38

48 Harris JE, Kowalski CJ, Walker SJ. Intrafamilial dentofacial associations for Class II, Division 1 probands. Am J Orthod 1975;67 (05):563-570

49 Korkhaus G. Investigations into the inheritance of orthodontic malformations. Dental Record 1930;50:271-280

50 Peck S, Peck L, Kataja M. Class II Division 2 malocclusion: a heritable pattern of small teeth in well-developed jaws. Angle Orthod 1998;68(01):9-20

51 Ruf S, Pancherz H, Class II. Class II Division 2 malocclusion: genetics or environment? A case report of monozygotic twins. Angle Orthod 1999;69(04):321-324

52 Marković MD. At the crossroads of oral facial genetics. Eur J Orthod 1992;14(06):469-481

53 Mills JRE. Principles and Practice of Orthodontics. Churchill Livingstone, Edinburgh;1982

54 Hotz R. Orthodontics in Daily Practice. Bern: Hans Huber Publishers; 1974
55 Nakasima A, Ichinose M, Nakata S, Takahama Y. Hereditary factors in the craniofacial morphology of Angle's Class II and Class III malocclusions. Am J Orthod 1982;82(02):150-156

56 Abass SK, Hartsfield JK. Investigation of genetic factors affecting complex traits using external apical root resorption as a model. Semin Orthod 2008;14:115-124

57 Al-Qawasmi RA, Hartsfield JK, Everett ET, Flury L, Liu L, Foroud $\mathrm{TM}$, et al. Genetic predisposition to external apical root resorption. Am J Orthod Dentofacial Orthop 2003;123(03):242-252

58 Al-Qawasmi RA, Hartsfield JK, Everett ET, Flury L, Liu L, Foroud $\mathrm{TM}$, et al. Genetic predisposition to external apical root resorption in orthodontic patients: linkage of chromosome-18 marker. J Dent Res 2003;82(05):356-360

59 Hartsfield JK, Morford LA. Genetic implications in orthodontic tooth movement. In: Shroff B, ed. Biology of Orthodontic Tooth Movement. Cham: Springer; 2016

60 Iwasaki LR, Gibson CS, Crouch LD, Marx DB, Pandey JP, Nickel JC. Speed of tooth movement is related to stress and IL-1 gene polymorphisms. Am J Orthod Dentofacial Orthop 2006;130(06): 698.e1-698.e9

61 Iwasaki LR, Crouch LD, Nickel JC. Genetic factors and tooth movement. Semin Orthod 2008;14:135-145 